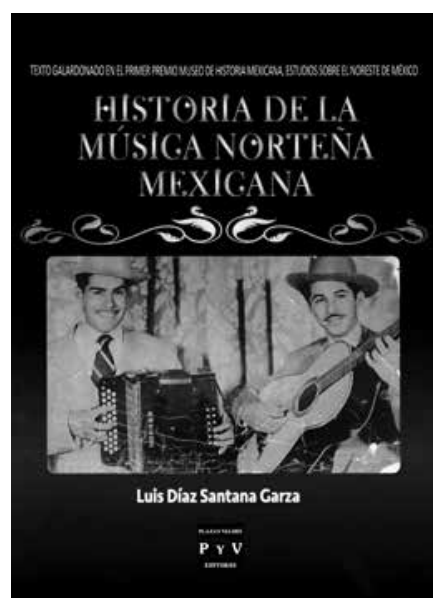

La norteña: A Story from both Sides of the River

JosÉ JUAN Olvera GudiÑo

Centro de Investigaciones y Estudios Superiores en Antropología Social-Noreste, Monterrey, Nuevo León, México jjolvera@ciesas.edu.mx

Desacatos 58 ,

septiembre-diciembre 2018, pp. 204-208
- Historia de la música norteña mexicana

Luis Diaz Santana Garza, 2016

Plaza y Valdés, México

\section{La norteña: una historia desde los dos lados del río}

\author{
JOSÉ JUAN OLVERA GUDIÑO
}

uando observo el auge en México de ciertas músicas populares en nuestra vida cotidiana, me viene a la mente la palabra "norteñización”. Este concepto fue acuñado en 1998 por Rafael Alarcón para estudiar el impacto de la migración internacional en la población de Chavinda, Michoacán. Desde 2009, he propuesto el concepto "norteñización musical de México" para designar esta especie de hegemonía de las culturas musicales del Norte del país — música norteña de acordeón y bajo sexto, música de banda, movimiento alterado, la música nortec, parte de la llamada música grupera, etc.- - en cada vez más espacios sociales, presenciales o virtuales, nacionales o transnacionales. Esta hegemonía es expresión de la fuerza económica e ideológica que se ha desarrollado en los estados del Norte de México durante el último medio siglo.

Lo anterior me lleva a reflexionar sobre la actitud de nuestras escuelas y facultades de música ante este fenómeno: indolente, por decir lo menos; soberbia, si uno quisiera pelea. Centradas en sus programas tradicionales, que acentúan la formación clásica o cuando mucho incluyen el estudio de algunas músicas tradicionales, ignoran casi por 
completo las emergencias que ocurren en la música popular, sus motivos, limitaciones o potencialidades, en fin, su papel en la vida de las personas.

Al trabajar con otra actitud, en la academia podemos entender el libro de Luis Díaz Santana Garza: Historia de la música norteña mexicana. Por “música norteña mexicana”, Díaz Santana se refiere a la música de conjunto norteño, que ha tenido como instrumentos centrales el acordeón diatónico y el bajo sexto. Esta definición incluye el denominado "conjunto texano" y su "conjunto music", que se ha tocado en el Sur del estado de Texas, antes de expandirse ambas músicas a otros lugares de Estados Unidos y a otros países de Latinoamérica y el mundo.

Este libro forma parte de una serie de aportaciones recientes que comienzan a ocuparse del notorio desbalance entre la gran presencia de esta música en nuestra vida social y el escaso conocimiento académico generado sobre ella. En particular, la que se produce en el Noreste del país.

Por mencionar sólo algunas obras, hablaremos de las aportaciones de Alfonso Ayala, "Un siglo de música popular (1900-2000)" (2014) y Desde el Cerro de la Silla. Origen y conformación del conjunto norteño en Monterrey (2003); de Luis Martín Garza, Raíces de la música regional en Nuevo León (2006), y las secciones de música tradicional y popular en los tomos de la colección Patrimonio cultural intangible de Nuevo León (2006-2016), que recupera prácticas y tradiciones de la música popular en varios municipios del estado, incluyendo la tradición del conjunto norteño. Otros aportes son del historiador Luis Omar Montoya Arias, quien habla de la expansión en Latinoamérica de la música norteña en su tesis doctoral (2014a), en ;Arriba el Norte! Música de acordeón y bajo sexto (2013), texto en dos tomos de la colección Testimonio Musical de México, que incluye una selección de melodías, y El síndrome de la nostalgia (2014b), que, entre otros temas, trata el papel de la mujer en el desarrollo de la música norteña. No olvidemos el reciente trabajo de Raquel Ramos
Rangel (2016), que analiza el papel de la música y la fiesta en una comunidad de Los Ramones, Nuevo León, en la que migrantes transnacionales y residentes locales reducen sus diferencias y conflictos al son de la música de conjunto norteño.

Estas obras representan una reacción ante la hegemonía mantenida, por lo menos desde la década de 1950, por académicos estadounidenses, en particular texanos, cuando se trataba de estudiar las músicas de la región, desde el punto de vista académico, ${ }^{1}$ ya sea con una perspectiva etnomusicológica o sociológica. Desde el mítico Américo Paredes, con su disertación doctoral sobre Gregorio Cortéz, en 1958, que luego fue publicada con el título "With his Pistol in his Hand": A Border Ballad and its Hero (1970), y el texto $A$ Texas-Mexican Cancionero (1976); pasando por Manuel Peña con The TexasMexican Conjunto (1996) y Música tejana (1999); José E. Limón (1983; 1994), y por último, la tesis doctoral de la etnomusicóloga Catherine Ragland, Música Norteña; Mexican Americans Creating a Nation between Nations (2009).

Ahora, ¿qué tiene qué decir de nuevo Luis Díaz Santana? En mi opinión, es el primer texto que discute con seriedad, desde el punto de vista historiográfico, con las tradiciones académicas de los dos países.

Tratar de manera científica los temas de la música popular, ya sea que se provenga de la musicología o de las ciencias sociales y humanidades, exige una actitud interdisciplinaria (Napolitano, 2007: 154). Esto es porque, por lo general, hay que hacer frente a los retos que plantea la dimensión histórica, la propiamente musicológica, relativa a sus estructuras musicales y a sus mediatizaciones, etc. En ese sentido, la cualidad principal de trabajo

Entiendo por región Noreste principalmente a los estados mexicanos de Coahuila, Nuevo León y Tamaulipas, así como el Sur del estado de Texas. 
de Díaz Santana es el ejercicio interdisciplinario. De la historiografía, su disciplina central, se recogen enfoques de la historia cultural y los estudios culturales. Su ventaja respecto a otros académicos es que no sólo habla desde la historia y las ciencias sociales. Díaz Santana es también un reconocido músico regiomontano, y como tal, puede desarrollar mejor esta perspectiva múltiple, para perseguir la respuesta a la pregunta: ¿cómo es que la música de conjunto norteño pasó de las cantinas a las principales escenas comerciales y a los salones de fiestas de las elites regiomontanas?

En Historia de la música norteña mexicana hay un trabajo serio de revisión de la literatura y los archivos importantes en México y Estados Unidos, aspecto que ha superado esfuerzos anteriores. Su propuesta de análisis histórico se complementa con entrevistas a personajes clave de esta cultura musical - hijos o herederos de los actores iniciales-, todo combinado con el análisis de las estructuras musicales.

El primer capítulo construye el contexto histórico que permite comprender la generación de una matriz cultural específica: la cultura de frontera y su particularidad en el Noreste mexicano. Para entender sus expresiones culturales, como la música de conjunto norteño, el autor explora la historia de Nuevo León y Texas, aunque para ello deba expandir los horizontes a la historia común con otros estados, como Tamaulipas y Coahuila, y examinar las condiciones ambientales relativamente similares: una breve vida administrativo-militar compartida, la lucha contra los pueblos originarios y el centralismo político. Es decir, el autor parte de la premisa de considerar a los estados norteños y al Sur de Texas como una región económica y cultural activa.

El segundo capítulo se concentra en la descripción de las tradiciones musicales del Noreste y el análisis de su diversidad y evolución. Destaca el eje identitario regional sobre el cual se tejen estas tradiciones. Subraya la tensión y oposición que algunas de estas músicas han mantenido ante la identidad nacional en proceso de construcción durante el siglo xx y la compleja otredad que se construye al otro lado del río Bravo, a partir de las guerras contra Texas y Estados Unidos. Aquí aparece, a mi ver, una de las aportaciones más importantes del libro, puesto que su autor destaca las tensiones entre regionalismo y nacionalismo posrevolucionario, que ocupan buena parte de la literatura académica. Al mismo tiempo, centra su atención en la construcción histórica de la región, que incorpora migraciones extranjeras a uno y otro lado de la frontera, sea por conflagraciones bélicas o desarrollos industriales. De esta manera, explica el elaborado entramado que da origen a la polka, el chotis, la redova, el vals, a ambos lados del río Bravo. Lo anterior ayuda a explicar diversidades y complejidades detrás de una música que puede parecer simple y sencilla a la mirada actual.

La música de conjunto bebe de otras fuentes, como la canción, el corrido y el huapango. En este sentido, Díaz Santana propone entender la aparición del huapango norteño como un desarrollo de migrantes potosinos asentados en la ciudad de Monterrey. En relación con los ensambles en los que se desarrollan estas músicas pioneras, destaca, como otros autores, el papel de las bandas militares, las orquestas típicas, los tamborileros y el conjunto de Los Montañeses del Álamo.

Los últimos tres capítulos desarrollan de lleno el tema del conjunto norteño y corresponden a: 1) su etapa inicial, arranque del siglo Xx hasta mediados de la década de 1940; 2) su consolidación en México y Estados Unidos, hasta mediados de la década de 1970, y 3) sus tendencias recientes, incluyendo el auge del narcocorrido. Me interesa destacar algunas de sus aportaciones en estos tres capítulos, en relación con la literatura académica que se ha desarrollado hasta la fecha.

La primera es que en el libro se despliega la mejor discusión académica sobre el origen del bajo sexto que yo haya revisado. Esto es clave, toda vez que el bajo sexto y el acordeón han sido referentes identitarios 
indiscutibles de la llamada música de conjunto norteño. Al recoger contribuciones de otros autores y discutirlas a profundidad, Díaz Santana propone una teoría sobre su origen y evolución, que intenta explicar la evolución del bajo sexto a partir de evidencia empírica, a la que respalda con una sólida revisión historiográfica.

Hay varias ideas de cómo surgió este particular instrumento de la organología popular mexicana; por ejemplo, la tesis de que el bajo sexto es una creación con influencia determinante del Bajío, llevada al Norte del país por los comerciantes huacaleros (Montoya, 2013: 191-198). De hecho, el Bajío habría sido el que contribuyó de manera principal a las influencias con las que se construyó la música norteña misma (p. 33).

Para Díaz Santana, la del bajo sexto es una historia de traslados, préstamos y mutaciones: "tiene una deuda con la guitarra española de cinco órdenes, conocida actualmente como guitarra barroca" (p. 100), cuyos descendientes, guitarra séptima y guitarra sexta de cuerdas dobles, aún se escuchaban a principios del siglo pasado. Con base en lo dicho por el músico e investigador Eloy Cruz, opina que el bajo sexto es una variante de la guitarra sexta de cuerdas dobles. Hace caso al académico mexicano Arturo Chamorro, al considerar, además, que este instrumento se deriva de la guitarra huapanguera o quinta. Por ello es posible pensar que los ancestros del bajo sexto provienen de la migración de la Huasteca a la zona fronteriza y Monterrey a finales del siglo XIX y principios del XX. Aun así, reconoce que ignora su origen, pero está seguro de que se consolidó en la frontera.

Díaz Santana sostiene también que "al modificar la guitarra séptima o la sexta de cuerdas dobles, para hacer más baja la afinación y grande la caja, podría emplearse en el registro que hay entre la guitarra y el bajo de armonía en las orquestas típicas, o también se adecuaba para acompañar mejor al acordeón" (p. 132). Su resonancia alternaba con la onmipresencia melódica y armónica del acordeón en los contextos festivos rurales, previos a la aparición de los megáfonos.

La segunda aportación de estos últimos capítulos es señalar la ausencia entre ciertos académicos estadounidenses, como Manuel Peña o José E. Limón, de la contribución que los músicos mexicanos de la frontera noreste tuvieron en el desarrollo de la música de conjunto en Texas. Varios músicos iniciales del conjunto norteño consolidaron una carrera artística y grabaron en Texas, e hicieron de la norteña una música transnacional, que cruzó desde municipios de Tamaulipas, como Reynosa, o de Nuevo León, como Terán, u otros lugares de la región, en busca de una mejor vida.

El papel de Pedro Ayala, Ramiro Cavazos o Agapito Zúñiga, como músicos mexicanos, no aparece en esa bibliografía. Esta atención centrada en un solo lado de la frontera - el americano, el del valle del río Grande, como se denomina allá el río Bravo - ya ha sido advertida por el etnomusicólogo Alejandro Madrid (2011: 8), como una característica que limita a los llamados estudios fronterizos, aunque también puede explicarse como reacción de estos académicos al proceso que ignoraba los aportes del Sureste texano en el proyecto nacional de Estados Unidos.

Como he dicho en otros lugares, la influencia ha sido mutua y vale mi metáfora de las corrientes incesantes de influencia de México a Estados Unidos, como marejadas o crecidas de un río, ligadas a corrientes migratorias, las cuales, a su vez, están relacionadas con procesos revolucionarios o económicos, que alimentan lo que Díaz Santana llama intertextualidad entre ambas culturas.

La Historia de la música norteña mexicana, de Díaz Santana, contribuye a historiar la nueva matriz cultural que, como el Caribe durante cinco siglos, está siendo protagonista en la construcción de las culturas mexicanas. Esta nueva matriz surge de diversas interacciones históricas. Por un lado, está la interacción 
de quienes se quedaron del otro lado, con el resto de la sociedad estadounidense en construcción. Por el otro, la interacción entre los mexicanos de este lado, con las sucesivas olas migratorias y la construcción de las comunidades transnacionales. De ahí, vale la pena preguntarse, con Luis Díaz Santana, ¿por qué esta música recibe poca atención? ¿Se debe acaso a que, tanto en México como en Estados Unidos, esta música celebra la otredad, que todavía es perturbadora en el contexto de ambos discursos nacionalistas? D

\section{Bibliografía}

Alarcón, Rafael, 1988, “El proceso de norteñización: impacto de la migración internacional en Chavinda, Michoacán”, en Thomas Calvo y Gustavo López (coords.), Movimientos de población en el Occidente de México, Centro de Estudios Mexicanos y Centroamericanos/El Colegio de Michoacán, Zamora, pp. 337-357.

Ayala, Alfonso, 2003, Desde el Cerro de la Silla. Origen y conformación del conjunto norteño en Monterrey, Herca, Monterrey.

__, 2014, "Un siglo de música popular (1900-2000)", en Biblioteca de las artes de Nuevo León, t. II: Artes escénicas, Consejo para la Cultura y las Artes de Nuevo León, Monterrey, pp. 287-316.

Garza, Luis Martín, 2006, Raíces de la música regional en Nuevo León, Fondo Estatal para la Cultura y las Artes de Nuevo León/Consejo para la Cultura y las Artes de Nuevo León, Monterrey.

Limón, José E., 1983, “Texas-Mexican Popular Music and Dancing: Some Notes on History and Symbolic Process”, en Latina American Music Review, vol. 4, núm. 2, pp. 229-246.

, 1994, Dancing with the Devil: Society and Cultural Poetics in Mexican-American South Texas, University of Wisconsin Press, Madison. Madrid, Alejandro (ed.), 2011, Transnational Encounters. Music and Performance at the U.S.-Mexico Border, Oxford University Press, Oxford.

Montoya Arias, Luis Omar (coord.), 2013, iArriba el Norte...! Música de acordeón y bajo sexto, Instituto Nacional de Antropología e Historia/ Consejo Nacional para la Cultura y las Artes, México.

—_ 2014a, La norteña en Latinoamérica o el transnacionalismo musical cosmopolita en las periferias, tesis de doctorado en historia, Centro de Investigaciones y Estudios Superiores en Antropología Social-Peninsular, Mérida.

, 2014b, El sindrome de la nostalgia, Universidad de Guanajuato, Guanajuato.

Napolitano, Marcos, 2007, “História e música popular: um mapa de leituras e questões”, en Revista de História, núm. 157, pp. 153-171. Disponible en línea: <http://www.revistas.usp.br/revhistoria/article/view/19066/21129>. Consultado el 2 de marzo de 2015.

Paredes, Américo, 1970, "With his Pistol in his Hand": A Border Ballad and its Hero, University of Texas Press, Austin.

, 1976, A Texas-Mexican Cancionero, University of Illinois Press, Urbana.

Patrimonio cultural intangible de Nuevo León, 2006-2016, tt. 1-9, Consejo para la Cultura y las Artes de Nuevo León, Monterrey.

Peña, Manuel, 1996, The Texas-Mexican Conjunto, University of Texas Press, Austin.

,1999, Música tejana, Texas A \& M University Press, Texas.

Ragland, Catherine, 2009, Música Norteña: Mexican Americans Creating a Nation between Nations, Temple University Press, Filadelfia.

Ramos Rangel, Raquel, 2016, Entre músicas y silencios. La cohesión y construcción social de un pueblo en las fiestas de Los Ramones, Nuevo León, México, tesis de maestría en antropología social, Centro de Investigaciones y Estudios Superiores en Antropología SocialNoreste, Monterrey. 